\title{
Pequenas centrais hidrelétricas brasileiras: propostas no gerenciamento de plano de risco ambiental na geração de gases de efeito estufa
}

\section{Leverson Ferreira Chaves}

Unyleya Educacional. Curso de Pós-Graduação lato sensu em Gestão de Riscos e Emergências Ambientais. SAI. Trecho 17, Rua 10, Lote 455. Guará. Brasília-DF, Brasil (CEP 71200-228). E-mail: leversonchaves@yahoo.com.br.

Resumo. Os reservatórios das pequenas centrais hidrelétricas (PCH) brasileiras, consideradas fontes de energia renovável, passaram a ser alvo de especulações acerca da geração de gases de efeito estufa (GEE) pela produção biogênica do dióxido de carbono e do metano. Com o aumento da demanda energética e o incremento da construção de hidrelétricas é mister que os planos de gerenciamento de risco ambiental estimulem a mitigação e o controle dos GEE em um mundo sob o risco de aquecimento global. 0 gerenciamento de planos de risco ambiental levando em consideração os principais fatores que influenciam as emissões de GEE é escasso. Sendo assim, considerar as emissões do dióxido de carbono e do metano no gerenciamento de plano de risco ambiental dos reservatórios é importante para a geração de medidas sustentáveis de mitigação e controle dos potenciais problemas relacionados aos GEE nas pequenas centrais hidrelétricas e seus riscos. Este trabalho tem como objetivo fornecer, através de informações de material bibliográfico, propostas básicas no gerenciamento de plano de risco ambiental para emissões de GEE em pequenas centrais hidrelétricas através dos principais fatores que influenciam as emissões nos reservatórios em face dos estudos que apontam para um mundo futuro sob os efeitos de um aquecimento global.

Palavras-chave: PCH; GEE; Gerenciamento riscos ambientais.

Abstract. Brazilian small hydroelectric plants: Proposals in the management of environmental risk plan in the generation of greenhouse gases. The reservoirs of small Brazilian hydroelectric power stations (HPS), considered a source of renewable energy, became the target of speculation about the generation of greenhouse gases (GHGs) by the biogenic production of carbon dioxide and methane at these sites. With increased energy demand and increased hydroelectric construction, it is imperative that environmental risk management plans encourage mitigation and control of greenhouse gases in a world at risk of global warming. The management of environmental risk plans taking into account the
Recebido:

$11 / 12 / 2018$

Aceito:

12/07/2019

Disponível on line:

13/07/2019

Publicado:

$31 / 08 / 2019$

Artigo aberto

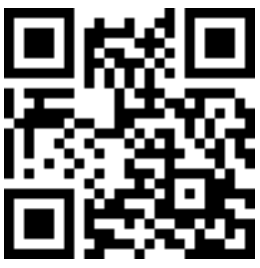

ORCID

(D) $0000-0002-2699-5486$

Leverson Ferreira

Chaves 
main factors influencing emissions of GHG is scarce. Therefore, considering the emissions of carbon dioxide and methane in the management of environmental risk plan of the reservoirs is important for the generation of sustainable measures of mitigation and control in the potential problems related to the greenhouse gases in the small hydropower plants and their risks. This paper aims to provide, through bibliographic material information, basic proposals in the management of environmental risk plan for greenhouse gas emissions in small hydropower plants through the main factors that influence the emissions in the reservoirs in the face of studies that point to a world under the effects of global warming.

Keywords: HPS; GHG; Environmental risk planning.

\section{Introdução}

Apesar de ser considerada uma fonte de energia renovável e limpa (Carvalho, 2015), desde a década de 1990 especula-se que as hidrelétricas, por meio de seus reservatórios, contribuam para a intensificação do efeito estufa, através da liberação de gases oriundos do produto da decomposição do material orgânico em sua bacia de acumulação (Santos et al., 2008). 0 dióxido de carbono $\left(\mathrm{CO}_{2}\right)$ e o metano $\left(\mathrm{CH}_{4}\right)$, produzidos na bacia de acumulação, comprovadamente interagem com a radiação infravermelha na atmosfera causando a intensificação do efeito estufa natural, também chamado aquecimento global (Royer et al., 2007; Pachauri e Meyer, 2015; Ito e Franco, 2018).

A geração hidrelétrica no Brasil tem garantido a produção de cerca de 95\% da eletricidade consumida no país nos últimos anos; e, em termos absolutos, o Brasil é o terceiro maior produtor de energia hidrelétrica no mundo (ANEEL, 2017). O incremento da demanda da implantação de usinas hidrelétricas no país deve-se, sobretudo, ao seu vasto potencial hídrico e a competitividade econômica que essa fonte de energia proporciona (Goldemberg e Moreira, 2005).

Os reservatórios e lagos podem apresentar saturação de carbono pela produção de metano e pelo metabolismo do dióxido de carbono onde as taxas de respiração são maiores do que as taxas de produção primária, ocorrendo uma tendência à saturação e a liberação desses gases para a atmosfera (Cole e Caraco, 1998; Dean e Gorham, 1998). Alguns estudos apontam que reservatórios podem atuar como sumidouros de carbono (Sikar et al., 2009; Ometto et al., 2013; Mendonça et al., 2015), a despeito desses estudos não considerarem a localização dos reservatórios estudados, a logística e a metodologia aplicada (Fearnside, 2016).

Os principais fatores que influenciam as emissões oriundas das hidrelétricas incluem a localização geográfica, o tipo de vegetação do entorno, a temperatura, a sazonalidade, o tamanho, a profundidade do reservatório, a profundidade da tomada de água das turbinas e a operação da barragem; envolvendo assim, muitas incertezas na estimativa dos valores de emissão para os reservatórios em todo mundo (Sbrissia, 2008). As hidrelétricas são consideradas responsáveis por impactos negativos (sociais e ambientais) em contraste com aspectos positivos, já que são uma fonte de água potável, lazer, piscicultura, irrigação, turismo, desenvolvimento local, comércio e transporte; além de agregar segurança para a adaptação às mudanças climáticas ao atuarem como elemento regulador de vazões excessivas e 
elemento de suprimento em épocas de seca (Carvalho, 2015).

0 quinto relatório do Painel Intergovernamental sobre Mudanças Climáticas (Pachauri e Meyer, 2015) demonstra que houve um incremento dos gases de efeito estufa (GEE) nos últimos anos em decorrência da ação antrópica, o que pode elevar a temperatura do planeta e acarretar, principalmente na América Latina, mudanças no padrão de precipitação das chuvas, redução da água no solo, salinização e desertificação (Vieira, 2018). No que concerne às hidrelétricas e seus reservatórios, essas são consideradas (Souza e Galvani, 2009) lagos de origem antrópica oriundas de mudanças drásticas e abruptas de um ecossistema original ou degradado.

O desenvolvimento sustentável visa integrar crescimento econômico e meio ambiente considerando as gerações futuras (Silva et al., 2010). A maioria dos estudos de exequibilidade do aproveitamento hidrelétrico (Neoenergia, 2009) parecem visar apenas a viabilidade ambiental, social e econômica dos projetos para fins de licenciamento, sem considerar os efeitos das emissões desses empreendimentos no tempo e no espaço, isto é, de forma insustentável. Os estudos de gerenciamento ambiental apresentam inúmeras vantagens ao integrar processos naturais, sociais e econômicos, cuja organização das informações permite estratificar os ambientes naturais, correlacionando-os com as atividades produtivas que serão desenvolvidas nos mesmos (Marques, 2003).

0 gerenciamento de planos de riscos ambientais levando em consideração as causas das emissões de GEE de acordo com os parâmetros particulares de cada reservatório são escassos, contudo, poderiam viabilizar os licenciamentos, além de tornar as hidrelétricas mais sustentáveis. Sendo assim, considerar as emissões desses gases no gerenciamento de planos de risco ambiental das barragens hidrelétricas é importante para a geração de medidas sustentáveis de mitigação e controle nos potenciais problemas relacionados aos GEE e seus riscos na contribuição de um iminente aquecimento global.

Este trabalho tem como objetivo fornecer, através de informações de material oriundo de pesquisa bibliográfica, propostas básicas no gerenciamento de plano de risco ambiental para emissões de carbono em hidrelétricas através dos principais fatores que influenciam as emissões nos reservatórios em face dos estudos que apontam para um mundo futuro sob os efeitos de um aquecimento global.

\section{Os fatores que influenciam as emissões de GEE}

A interação entre o homem e o meio ambiente sempre foi caracterizada por conflitos mútuos, onde a noção de risco ambiental é o resultado da relação entre a ameaça e a vulnerabilidade dentro dessa interação (Souza e Zanella, 2009). A classificação dos riscos ambientais no gerenciamento de risco visa compartimentá-los de forma a lidar melhor com as intercorrências ambientais de cada segmento em determinado empreendimento (Marques, 2003), minimizando os danos.

A Estratégia Internacional de Redução de Desastres, criada pela Organização das Nações Unidas (ISDR, 2007), classifica os riscos em três categorias: riscos naturais (geológicos, hidrometeorológicos e biológicos), riscos tecnológicos (acidentes, explosões, poluição associada a falhas de operação) e riscos de degradação ambiental (desflorestamento, mudanças climáticas, extinção da biodiversidade), e as pequenas centrais hidrelétricas no Brasil podem ser configuradas nas três categorias.

Para Sbrissia (2008), a localização geográfica, o tipo de vegetação do entorno, a temperatura, a 
sazonalidade, o tamanho, a profundidade do reservatório, a profundidade da tomada de água das turbinas e a operação da barragem são os principais fatores que influenciam as emissões de GEE nos reservatórios. Na construção de um plano de gerenciamento de riscos ambientais nas emissões de gases em pequenas centrais hidrelétricas brasileiras seria crucial classificar esses fatores de forma que o gerenciamento fosse melhor compartimentado (Marques, 2003) para minimizar os danos.

A relação entre a localização geográfica, a temperatura, a sazonalidade e a vegetação de entorno estão intimamente relacionadas com a posição geográfica no planeta onde as hidrelétricas são construídas. No Brasil, um país tropical, essa relação é ainda maior, devido às altas temperaturas e a presença de florestas e vegetação tropical. Esses fatores poderiam ser considerados naturais, e se configurariam dentro dos riscos naturais na classificação dos riscos elaborada pela Estratégia Internacional de Redução de Desastres (ISDR, 2007). 0 tamanho do reservatório e a profundidade do mesmo poderiam ser considerados fatores estruturais, e, portanto, elementos de transição entre riscos naturais e riscos tecnológicos. A profundidade da tomada de água das turbinas e a operação da barragem poderiam ser considerados fatores operacionais, e na elaboração do plano de gerenciamento de riscos, configurar-se-iam dentro dos riscos tecnológicos. Os riscos de degradação ambiental classificado pela Estratégia Internacional de Redução de Desastres (ISDR, 2005) parecem configurar os efeitos e os resultados oriundos dos riscos naturais e tecnológicos causados pela não observação dos mesmos na construção dos empreendimentos, e, portanto, poderiam ser configurados dentro dos fatores naturais, estruturais e operacionais no gerenciamento de riscos ambientais nas emissões de GEE das pequenas centrais hidrelétricas

brasileiras.

\section{Fatores naturais e plano de gerenciamento de risco ambiental}

No que concerne aos fatores naturais, isto é, a localização geográfica, a temperatura, a sazonalidade e o tipo de vegetação do entorno dos reservatórios, as pequenas centrais hidrelétricas são potencialmente promissoras na geração de GEE. Sendo assim, considera-las nos estudos de impacto ambiental e no licenciamento poderiam gerar informações pertinentes para um plano de risco ambiental promissor.

Os fatores naturais estão intimamente relacionados entre si. A temperatura, tipo de vegetação do entorno e a sazonalidade apresentam características próprias dentro de uma determinada localização no globo. Um plano de gerenciamento de risco ambiental considerando os fatores naturais não deverá ter a pretensão de controle sobre esses fatores, mas de análise prévia ao empreendimento, pois poderão ser inviáveis ou impossíveis de modular. Em tempos de aquecimento global, muitos desses fatores sofrerão alterações e incrementos de forma abrupta, o que justifica um plano de gerenciamento de risco ambiental como ferramenta de ajuda no pensamento global acerca das mudanças climáticas.

\section{Localização geográfica}

A localização geográfica brasileira e suas características físicas repleta de montanhas e planaltos determinaram, historicamente e no futuro, a criação de um parque gerador de energia elétrica predominantemente hídrica (Eick, 2010) em larga escala no país. A pluviosidade elevada e o pH baixo promovem o intemperismo, a lixiviação, a disponibilidade de elementos químicos (Esteves, 1988), mesmo o Brasil estando situado em uma região do globo geologicamente antiga (com exceção dos Andes), de solo pobre e limitada 
disponibilidade de nutrientes (Teixeira et al., 2009). Por sua posição nos trópicos, as altas temperaturas médias (maior difusão dos GEE para o ar) e a vegetação exuberante (material em decomposição) favorecem a emissão profusa do dióxido de carbono e do metano nos reservatórios brasileiros (Esteves, 1988). De acordo com Fearnside (2008), considera-se que represas tropicais emitem mais GEE do que represas em áreas temperadas $\mathrm{e}$ boreais.

As emissões, considerando a localização geográfica, possuem repercussão tanto ao nível global (tropical, temperado e boreal) quanto ao nível regional (norte, nordeste, centrooeste, sul e sudeste). A localização geográfica específica da pequena central hidrelétrica no país pode apresentar variação nos valores de emissão, mesmo entre represas em uma mesma região. Represas variam amplamente na quantidade de GEE que elas emitem. Considera-se que represas tropicais emitem mais gases de efeito estufa do que represas em áreas temperada e boreal, mas é um engano pensar que só represas tropicais emitem gases. Dentro dos trópicos há também variação em emissões (Fearnside, 2008).

0 gerenciamento dos riscos observando a localização geográfica de uma pequena central hidrelétrica poderia contribuir para minimizar altos valores de emissão apenas considerando a topografia, o revelo ou o clima do local onde a hidrelétrica seria construída. A composição e uso do solo da região (pecuária, agricultura, uso de fertilizantes e densidade populacional), a temperatura média, a sazonalidade e a vegetação típica da região nos estudos de impacto ambiental poderiam oferecer informações pertinentes para um plano de gerenciamento de risco ambiental na emissão de GEE.

Uma pequena central hidrelétrica brasileira construída no sul do país poderia apresentar valores diferentes de emissão de GEE em relação à outra construída no norte do país. Os menores valores de emissão relacionados à localização geográfica gerariam riscos menores e, portanto, seriam mais viáveis na produção de energia em face ao aquecimento global.

\section{Temperatura}

As variações de temperatura afetam os reservatórios tanto na bacia de drenagem ao entorno quanto dentro do reservatório. 0 aumento da temperatura e da precipitação, por vezes relacionado aos fatores meteorológicos e climáticos, permite o aporte alóctone de nutrientes oriundos do escoamento superficial a partir da bacia de drenagem do reservatório, acelerando a produtividade das plantas na zona litorânea dos mesmos e favorecendo o aumento da biomassa em decomposição e o consequente incremento da produção de metano (Esteves, 1988).

0 aumento da temperatura da água favorece a diminuição do oxigênio próximo ao sedimento, sobretudo nos sedimentos em menor profundidade (um fator estrutural) no reservatório, gerando o aumento da decomposição anaeróbica e uma maior taxa de formação do metano (Bastviken, 2009).

Segundo Esteves (1988), a estratificação térmica (diferenças de temperatura na água gerando camadas com diferentes densidades que não se misturam) das massas de água nos reservatórios tropicais de profundidade reduzida ocorre diariamente na maioria dos casos. Um padrão diferenciado ocorre em reservatórios profundos que podem permanecer estratificados durante todo o ano, com desestratificação apenas no inverno brasileiro. 0 período de verão em regiões tropicais e o aumento da pluviosidade elevam o nível da água gerando estratificações duradouras, às vezes abrangendo todo o verão. A estratificação e a desestratificação estão relacionados à difusão do metano na coluna de água e sua emissão nos reservatórios. 
A temperatura é um fator relacionado à localização geográfica. Dentro do plano de gerenciamento de risco ambiental, é extremamente importante considera-la, pois na produção e na emissão do dióxido de carbono e do metano, a temperatura é um fator crucial. A temperatura afeta a produção primária do reservatório e a vegetação do entorno, além de influenciar profundamente a bacia de drenagem e o uso do solo onde a pequena central hidrelétrica será construída. A dinâmica dos nutrientes, o aporte alóctone, a produção primária autóctone e alóctone, a temperatura da água e sua estratificação, todos esses parâmetros são afetados pela temperatura, e, portanto, a produção e a emissão de GEE.

\section{Sazonalidade}

A sazonalidade (influência das estações secas e chuvosas) reflete 0 regime de precipitação em regiões tropicais e subtropicais com pulsos de inundação que dinamizam os sistemas de produtividade, influenciando profundamente a produção e emissão dos GEE (Esteves, 1988). Os períodos de estiagem e cheia promovem alterações nos níveis da água que influenciam a concentração de nutrientes (Almeida et al., 2007), a produtividade e a decomposição, afetando a produção e a emissão de GEE nos reservatórios (Fearnside, 2008). Além disso, a sazonalidade é relevante para a tomada de água das turbinas nas pequenas centrais hidrelétricas e na relação dessa operação com as emissões de metano produzido no fundo do reservatório (Santos et al., 2008).

Em se tratando de um fator natural dentro do plano de gerenciamento de risco ambiental, a sazonalidade estaria configurada dentro da análise prévia do empreendimento através de registros de estiagem e chuva local e suas influências na região (vegetação, volume de água no reservatório, produtividade e produção de metano). A sazonalidade afetaria a profundidade do reservatório, e uma das grandes questões das hidrelétricas em relação à emissão de metano ocorre durante a tomada de água pelas turbinas (Santos et al., 2008). 0 plano de risco ambiental para emissão de GEE nas pequenas centrais hidrelétricas seria contundente na dinâmica operacional das hidrelétricas, e o conhecimento prévio da sazonalidade seria importante nesse processo.

\section{Tipo de vegetação do entorno}

De acordo com a localização geográfica, a bacia de drenagem onde uma hidrelétrica é instalada pode apresentar vegetação bem diversificada, desde florestas tropicais até pastagens. A caracterização da vegetação na prérepresa (antes da instalação) seria de extrema importância no plano de gerenciamento de risco ambiental, pois a produção primária é fonte de carbono na formação dos GEE, sobretudo em uma área pré-represa coberta de floresta tropical.

Em reservatórios, a fonte de carbono advém dos estoques da produção primária autóctone, dos estoques presentes na vegetação e no solo antes do enchimento do reservatório, bem como do carbono na forma dissolvida ou particulada que chega ao reservatório proveniente dos rios e córregos da bacia de drenagem (Esteves, 1988). As árvores que morrem quando o reservatório é inundado liberam carbono pela decomposição acima da água, isto é, nas porções das árvores mortas projetadas sobre a superfície do reservatório, bem como em queimadas durante eventos de declínio extremo do nível da água (Fearnside, 2008).

Em relação a área pré-represa constituída originalmente por florestas, as emissões de GEE são particularmente altas em áreas tropicais devido a emissão de dióxido de carbono e metano na decomposição das árvores acima da lâmina de água deixadas em pé enquanto 
os reservatórios enchem e pela decomposição sob condições anaeróbicas no fundo do reservatório. Não há consenso de que a madeira das árvores submersas seja uma fonte significativa de carbono para a produção de metano, porque $o$ tecido vegetal lignificado decompõe-se a uma taxa extraordinariamente lenta sob condições anaeróbicas; diferente da vegetação herbácea que se decompõe rapidamente, liberando assim, seu estoque de carbono na forma de gases para a atmosfera (Fearnside, 2008).

Em relação a área pré-represa composta de pastagens, não há diferença significativa para os estoques de carbono do solo entre os ambientes de mata, pasto degradado e pasto produtivo, mesmo com diferentes idades de uso e em diferentes profundidades de solo. Segundo Costa et al. (2000), após vinte e oito anos de uso com pastagem bem e mal manejada, em média $62 \%$ do carbono orgânico do solo ainda era derivado da floresta original até $30 \mathrm{~cm}$ de profundidade do solo.

Outra fonte de emissões provém de árvores mortas perto da margem do reservatório quando o nível da água sobe e alcança as raízes. 0 contorno irregular da margem dos reservatórios e as margens das muitas ilhas criadas durante o enchimento afetam significativamente, pois as árvores mortas se decompõem, liberando dióxido de carbono mesmo que uma floresta secundária se desenvolva. Presume-se que a mortalidade seja de $90 \%$ na faixa até $50 \mathrm{~m}$ além da margem do reservatório, e de $70 \%$ na faixa entre $50 \mathrm{~m}$ a $100 \mathrm{~m}$ dessa margem (Fearnside, 2008). A decomposição segue o mesmo curso que em áreas derrubadas para a agricultura, e presume-se que a floresta secundária cresça à mesma taxa que as capoeiras em pousios de agricultura itinerante (Fearnside, 2008).

A produção autóctone do reservatório também é uma substancial fonte de carbono, pois o aporte de nutrientes favorece a produção primária. Alguns vegetais como as macrófitas flutuantes são capazes de produzir grande quantidade de biomassa, que entre outros efeitos negativos, contribuem para aumentar o déficit de oxigênio, favorecendo a produção de metano (Esteves, 1988). A construção de represas produz inúmeras alterações ambientais, que favorecem o crescimento destes vegetais pela intensa liberação de nutrientes oriundos da decomposição da biomassa das áreas inundadas, contribuindo para a produção de dióxido de carbono e metano, visto que não retiram o dióxido de carbono da coluna de água, mas diretamente da atmosfera (Ram et al., 2003). A pluviosidade favorece frequentemente o metabolismo aquático ao aumentar o aporte da lixiviação orgânica terrestre. A intensificação das chuvas também incrementa o aporte de nitrogênio e fósforo nos lagos, favorecendo o metabolismo autotrófico, especialmente em áreas urbanas e agrícolas (Verburg et al., 2003).

O plano de gerenciamento de risco ambiental consideraria retirar a vegetação das áreas alagáveis antes da construção da barragem, utilizando a biomassa recolhida de forma sustentável (reaproveitamento, adubo, aterros, outros). Isso, além de diminuir as fontes de carbono oriundas da construção do reservatório, confere destino adequado para minimizar a produção de metano na decomposição da biomassa descartada.

A vegetação formada durante uma estiagem em áreas antes inundadas (zona de deplecionamento) pode ser modulada pelo controle do nível do reservatório ou até mesmo pelo manejo das mesmas, impedindo o desenvolvimento da vegetação e sua posterior decomposição (formação metano) quando o reservatório tiver seus níveis de água elevados.

As áreas de pastagens inundadas não oferecem muito risco na produção de metano pelo baixo estoque de carbono (Costa et al., 2000), exceto em áreas com uso de fertilizantes, o que poderia incrementar a produção primária em 
eventos de inundação e lixiviação. Isso seria passível de verificação prévia no estudo de impacto ambiental ou no plano de gerenciamento de risco ambiental quanto ao uso do solo. O plantio de espécies vegetais ao redor dos reservatórios cuja biomassa produza pouco metano pelo baixo estoque de carbono seria viável, podendo ser até mesmo uma ferramenta no gerenciamento de risco ambiental. 0 plantio em sucessão dessas potenciais espécies ao longo dos reservatórios poderia minimizar a lixiviação, o aporte de nutrientes e garantir a decomposição em baixo risco de produção de metano em eventuais processos de inundação e elevação do nível dos reservatórios.

A localização geográfica e a vegetação adaptada na região onde o empreendimento seria instalado deveriam ser consideradas nessa abordagem. Algumas espécies são críticas e possuem papel ecológico fundamental para a manutenção da biodiversidade de ecossistemas aquáticos e, portanto, não podem ser removidas (Silva et al., 2010).

\section{Fatores estruturais e plano de gerenciamento de risco ambiental}

Os fatores estruturais, isto é, o tamanho do reservatório e a profundidade do mesmo podem ser considerados, dentro do plano de risco ambiental, como fatores de transição entre os fatores naturais e os fatores operacionais. Enquanto os fatores naturais são melhores gerenciados para minimizar as emissões de GEE antes da instalação do empreendimento, os fatores estruturais são melhores gerenciados antes e durante o processo de instalação.

O tamanho do reservatório e sua profundidade estão condicionados à intenção do projeto na vazão para a geração de energia. Nas emissões de metano, a profundidade do reservatório, devido a relação deste com a formação do gás no sedimento, é um ponto importante nos planos de gerenciamento de risco ambiental, principalmente nas emissões na tomada de água das turbinas.

\section{Tamanho do reservatório}

Nos últimos anos, com a expressão da opinião pública e da pressão sobre os órgãos ambientais, os novos empreendimentos têm sido feitos de forma que os reservatórios atuem em "fio d'água", para que áreas extensas não sejam inundadas pelo reservatório.

Na modalidade a "fio d'água", a usina gera energia seguindo as flutuações hídricas anuais do rio, isto é, de acordo com a quantidade de água existente. $\mathrm{Na}$ época da cheia, a hidrelétrica usa toda a sua capacidade para gerar energia, enquanto que, na época da estiagem, a mesma produz pouca energia. No caso da Usina de Belo Monte, localiza no Município de Altamira, Estado do Pará (Alves et al., 2018), por exemplo, as outras hidrelétricas das regiões abastecidas podem manter o nível de seus reservatórios elevados até que sejam utilizados na estiagem, quando a Usina de Belo Monte estará gerando pouca energia (Neoenergia, 2009).

Os meandros das margens dos reservatórios são formados em menor escala temporal em relação aos ecossistemas naturais sujeitos aos processos geológicos, e, por isso, apresentam diferenciadas características. Em função dessa formação, o afluxo de água dá-se preferencialmente ao longo do canal central, fazendo com que a maior parte do volume de água presente nos braços fique parcialmente isolada do corpo central na maior parte do tempo, o que permite a formação de compartimentos com diferenças na qualidade de suas águas (Pompeo et al., 2015).

A heterogeneidade dos braços em relação ao canal central é consistente, visto que o metabolismo litorâneo é alimentado por aportes terrestres que são retidos pela vegetação da margem. Assim, porção de áreas vegetadas, 
características do sedimento, flutuações do nível de água, exposição da margem e características da água estão relacionadas as emissões de metano nessa região (Wetzel, 1992). As regiões nos braços com pouca profundidade da coluna de água podem emitir mais metano devido ao acúmulo de matéria orgânica e nutrientes (Zheng et al., 2011).

No plano de gerenciamento de risco ambiental no que concerne ao tamanho do reservatório, o modelo "fio d'água" seria eficaz, pois a formação de meandros nos braços decorrente da inundação em menor escala temporal poderia ser minimizada pela vazão original do corpo hídrico. Os meandros formados em decorrência da construção da barragem poderiam ser trabalhados durante a retirada da vegetação, ou utilizar espécies vegetais de baixo estoque de carbono no entorno dos meandros, para que module o aporte da lixiviação e minimize a formação de biomassa.

\section{Profundidade do reservatório}

A profundidade do reservatório tem influência na emissão de GEE relacionado ao sedimento. Em águas rasas, parte do metano produzido no sedimento se desloca até a superfície via ebulição (liberação de bolhas); e em profundidades maiores que trinta metros, o metano é emitido através do processo de difusão, pois a pressão da coluna de água não possibilita a liberação de bolhas (Santos et al., 2005). As mudanças na profundidade dentro do reservatório afetam a emissão dos GEE para a superfície e para a atmosfera (St. Louis et al., 2000). 0 metano oriundo dos sedimentos mais profundos está mais sujeito a oxidação, porque se difunde lentamente na coluna de água, ao contrário do fluxo de ebulição. Quando não há oxigênio suficiente para decompor a matéria orgânica, em maiores profundidades, por exemplo, o regime anaeróbio é estabelecido (Bastviken, 2009). Nas camadas mais superficiais do reservatório, a concentração de oxigênio aumenta e as bactérias presentes nessas camadas do reservatório podem produzir dióxido de carbono a partir do metano e oxigênio. Nos primeiros estágios da decomposição são produzidos ácidos orgânicos, os quais são decompostos originando metano e dióxido de carbono (Santos et al., 2005). Assim, dependendo da profundidade do reservatório, há diferentes quantidades de gases de efeito estufa emitidas em diferentes áreas no mesmo reservatório.

0 plano de gerenciamento de risco ambiental, considerando a profundidade do reservatório, deveria permitir que os níveis de profundidade se mantivessem estáveis. Em regiões profundas no reservatório, em uma súbita mudança dos níveis da água, a mudança de pressão hidrostática poderia permitir a rápida liberação do metano no sedimento pelo fluxo de ebulição, aumentando os níveis de emissão. Além disso, a zona de deplecionamento gerada pela flutuação do nível da água (exposição de terra e crescimento rápido da vegetação herbácea de fácil decomposição) pode fazer com que o reservatório se comporte com uma "fábrica de metano" (Fearnside, 2008) ao remover dióxido de carbono da atmosfera pela fotossíntese e o reemitir na forma de metano quando a vegetação é inundada.

A produção de metano é baixa no primeiro ano de idade do reservatório (os estoques de carbono se decompõem nos primeiros anos depois do enchimento do reservatório), apresentando um pico aos quatros anos e declinando até os sete anos de idade, onde depois se mantém estável (Fearnside, 2008). Sendo assim, o plano de gerenciamento de risco ambiental deve considerar a idade e o nível de profundidade de toda a área do reservatório, para garantir menores valores de emissão. 


\section{Fatores operacionais e plano de gerenciamento de risco ambiental}

Os fatores operacionais dizem respeito a profundidade da tomada de água das turbinas e a operação das pequenas centrais hidrelétricas. Uma gama de trabalhos acerca dos GEE em hidrelétricas trata da estimativa das emissões oriundas da tomada de água das turbinas e dos vertedouros, com alguns estudos demonstrando valores superestimados de emissão das turbinas, mas corroborando profusamente com a produção e emissão nas zonas de deplecionamento.

Ações baseadas nos fatores estruturais poderiam minimizar as emissões de forma que os fatores operacionais pudessem agir como mecanismos de controle da capacidade mínima de operação dos reservatórios. Esse controle permitiria considerar a profundidade de modo que zonas de deplecionamento fossem evitadas, minimizando a produção e a emissão de GEE nos reservatórios.

\section{Profundidade da tomada de água das turbinas}

A estimativa de emissão de gases à jusante de represas logo após a passagem da água pelas turbinas é extremamente polêmica (Santos et al., 2008).

A concentração de metano cresce com a profundidade da coluna de água, apresentando concentrações mais elevadas em maiores profundidades (Santos et al., 2008). A água que passa pela turbina é geralmente tomada na parte de baixo da barragem e contém uma concentração maior de metano. A turbina cria uma mudança brusca na pressão e na temperatura da água, o que reduz a solubilidade do metano e do dióxido de carbono, fazendo com que a maior parte desses gases seja liberado para atmosfera assim que a água passa pela turbina (Fearnside, 2008).

Segundo Fearnside (2008), as emissões por ebulição e difusão podem ser relacionadas à concentração de metano a uma profundidade padronizada de $30 \quad \mathrm{~m}$. Alguns reservatórios apresentam esse limite como o limite inferior de tomada, e o limite superior em $15 \mathrm{~m}$ (Santos et al., 2008). A concentração de metano aumenta com a profundidade abaixo do oxiclinio em reservatórios, e algumas represas apresentaram um oxiclinio abrupto em 6 $\mathrm{m}$ e até em $10 \mathrm{~m}$ de profundidade (Fearnside, 2005).

Para o plano de gerenciamento de risco ambiental na geração de GEE em pequenas centrais hidrelétricas, a profundidade da tomada de água deveria passar por uma análise prévia. A análise das concentrações de GEE em diferentes profundidades seria muito importante para que a tomada de água das turbinas seja realizada de forma a minimizar as emissões. Outra opção seria a tomada em diferentes profundidades de acordo com a vazão, configurando uma inovação no empreendimento.

A profundidade da tomada de água das turbinas é uma questão contundente no plano de gerenciamento de risco ambiental para as pequenas centrais hidrelétricas, pois a produção de metano não ocorre logo após a formação do reservatório. A inviabilidade com relação as emissões no início do funcionamento da hidrelétrica justificam o plano de gerenciamento para os fatores naturais e estruturais. As represas em funcionamento podem analisar os valores de GEE em diferentes profundidades; e caso os valores de emissões da tomada de água das turbinas e dos vertedouros sejam consideráveis, seria necessário buscar estratégias de inovação no empreendimento ou trabalhar os fatores possíveis para diminuir os valores de emissão.

\section{Operação}

0 regime de operação em alguns reservatórios pode influenciar na emissão dos GEE, visto que a intensa geração de energia pode deplecionar o reservatório de forma muito rápida e 
possibilitar que ocorra profusa produção de metano nos braços dendríticos rasos e em regiões de pouca profundidade (Santos et al., 2008).

Embora as emissões sejam maiores nos primeiros anos após um ano da formação de um reservatório, a entrada contínua de carbono no reservatório por meio da decomposição da vegetação herbácea na zona de deplecionamento inundada anualmente indica que um nível apreciável de emissões será sustentado a longo prazo (Fearnside, 2008). A operação dos reservatórios seria importante para tentar minimizar as emissões devido ao deplecionamento, sobretudo em reservatórios onde o gerenciamento dos fatores naturais e estruturais não tivesse sido considerado.

O plano de gerenciamento de riscos poderia conferir aos operadores uma direção nos planos a serem seguidos para a operacionalização da hidrelétrica de forma a minimizar as emissões pelo deplecionamento. Como as emissões são substanciais anualmente pelo deplecionamento, o fator operação se torna crucial para mitigar as emissões de GEE.

\section{Conclusão}

A classificação dos fatores que influenciam as emissões de GEE nos reservatórios em naturais, estruturais e operacionais podem ajudar na compartimentalização dos riscos advindos da degradação ambiental nas pequenas centrais hidrelétricas brasileiras.

As propostas podem nortear planos particulares exclusivos para cada reservatório, de forma a implementar medidas que possam trazer sucesso no gerenciamento de riscos ambientais na emissão de GEE em pequenas centrais hidrelétricas, sobretudo em face a ameaça do aquecimento global.

A proposta de um plano específico de gerenciamento de risco ambiental nas emissões de GEE em pequenas centrais hidrelétricas está fora do objetivo desse trabalho, visto que as características particulares de cada pequena central hidrelétrica impedem que um plano de gerenciamento padrão seja elaborado. Os planos de gerenciamento específicos podem ser alvos de propostas de estudos futuros.

\section{Conflito de interesses}

0 autor declara não haver conflito de interesses.

\section{Referências}

Almeida, M. M. M.; Alexandre, A. M. B.; Araújo, L. F. P.; Figueiredo, M. C.B.; Rosa, M. F. Influência da sazonalidade na qualidade da água dos reservatórios da Bacia do Acaraú. Anais do XVII Simpósio Brasileiro de Recursos Hídricos, São Paulo, p. 1-11, 2007.

Alves, L. S.; Hage, S. N. S.; Pereira Júnior, A. A Usina Hidrelétrica de Belo Monte (Altamira, Estado do Pará, Norte do Brasil), o reassentamento urbano coletivo e a avaliação de impactos ambientais. Revista Brasileira de Gestão Ambiental e Sustentabilidade, $\begin{array}{llll}\text { v. } 5, & \text { n. } 9, & \text { p. } 49-74, & 2018 .\end{array}$ https://doi.org/10.21438/rbgas.050904

ANEEL-Agência Nacional de Energia Elétrica. Atlas de energia elétrica do Brasil. Brasília: ANEEL, 2017.

Bastviken, D. Methane. In: Likens, G. E. (Ed.). Encyclopedia of inland waters. Amsterdam: Elsevier, 2009. p. 783-805.

Carvalho, A.R.L. Reservatórios de regularização de usinas hidrelétricas: contribuição para uma matriz energética mais limpa. Rio de Janeiro: UFRJ/COPPE. 2015. (Tese de doutorado).

Cole, J. J.; Caraco, N. F. Atmospheric exchange of carbon dioxide in a low-wind oligotrophic lake measured by the addition of $\mathrm{SF}_{6}$. Limnology and Oceanography, v. 43, n. 3, p. 647-656, 1998. https://doi.org/10.4319/ lo.1998.43.4.0647

Costa, O. V.; Costa, L. M.; Fontes, L. E. F.; Araújo, Q. R.; Ker, J. C.; Nacif, P. G. S. Cobertura do solo e degradação de pastagens em área de domínio de Chernossolos no sul da Bahia. Revista Brasileira de Ciência do 
Solo, v. 24, n. 4, p. 843-856, 2000. https://doi.org/10.1590/S0100-0683200 0000400016

Dean, W. E.; Gorham, E. Magnitude and significance of carbon burial in lakes, reservoirs, and peatlands. Geology, v. 26, n. 6, p. 535-538, 1998.

Eick, G. Viabilidade econômica e financeira de uma pequena central hidrelétrica no Brasil. Florianópolis: Universidade Federal de Santa Catarina, 2010. (Trabalho de conclusão de curso).

Esteves, F. A. Fundamentos de Limnologia. 2. ed. Rio de Janeiro: Interciência, 1998.

Fearnside, P. M. Do hydroelectric dams mitigate global warming? The case of Brazil's Curuá-Una Dam. Mitigation and Adaptation Strategies for Global Change, v. 10, n. 4, p. 675-691, 2005. https://doi.org/10.1007/ s11027-005-7303-7

Fearnside, P. M. Hidrelétricas como "fábricas de metano": o papel dos reservatórios em áreas de floresta tropical na emissão de gases de efeito estufa. Oecologia Brasiliensis, $\begin{array}{lll}\text { v. } 12, & \text { n. } 1, \quad \text { p. } 100-115, & 2008 .\end{array}$ https://doi.org/10.4257/oeco.2008.1201.11

Fearnside, P. M. Interactive comment on "Organic carbon burial efficiency in a large tropical hydroelectric reservoir" by Mendonça et al. Biogeosciences Discussions, v. 12, suppl., C9548-C9548, 2016. https://doi.org/10.5194/bgd-1218513-2015

Goldemberg, J.; Moreira, J. R. Política energética do Brasil. Estudos Avançados, v 19, n. 55, p. 215-228, 2005. https://doi.org/ 10.1590/S0103-40142005000300015

ISDR - International Strategy for Disaster Reduction. Building the resilience of nations and communities to disasters. Genebra: ISDR, 2007. (Hyogo Framework for Action 2005-2015). Disponível em: <https://www.unisdr.org/we/inform/public ations/1037>. Acesso em: 20 out. 2018.

Ito, L. P. K.; Franco, M. P. V. Políticas para mitigação da emissão de gases de efeito estufa: propostas para o Estado de Minas Gerais. Revista Brasileira de Gestão Ambiental e Sustentabilidade, v. 5, n. 9, p. 89-110, 2018. https://doi.org/10.21438/ rbgas.050906
Marques, J.F. Elementos para uma abordagem ambiental integrada. In: Ortega, E. Engenharia ecológica e agricultura sustentável: exemplos de uso da metodologia energética-ecossistêmica. São Paulo: Analume, 2003.

Mendonça, R.; Kosten, S.; Sobek, S.; Cardoso, S. J.; Figueiredo-Barros, M. P.; Estrada, C. H. D.; Roland, F. Organic carbon burial efficiency in a large tropical hydroelectric reservoir. Biogeosciences Discussions, v. 12, p. 18513-18540, 2015. https://doi.org/ 10.5194/bg-13-3331-2016

Neoenergia. Aproveitamento hidrelétrico Belo Monte. Brasília: Neoenergia, 2009. Disponível em: <http://restritonorte energiasa.com.br/site/wp-content/uploads/ 2011/04/NE.Rima_.pdf>. Acesso em: 20 abr. 2018.

Ometto, J. P.; Cimbleris, A. C. P.; Santos, M. A.; Rosa, L. P.; Abe, D.; Tundisi, J. G.; Stech, J. L.; Barros, N.; Roland, F. Carbon emission as a function of energy generation in hydroelectric reservoirs in Brazilian dry tropical biome. Energy Policy, v. 58, p. 109-116, 2013. https://doi.org/10.1016/ j.enpol.2013.02.041

Pachauri, R. K.; Meyer, L. A. (Eds.). Climate change 2014: Synthesis report. Geneva, Switzerland: IPCC, 2015. Disponível em: <https://www.ipcc.ch/site/assets/uploads/2 018/05/SYR_AR5_FINAL_full_wcover.pdf>. Acesso em: 20 out. 2018.

Pompeo, M.; Carlos, V. M.; Nishimura, P. Y.; Silva, S. C.; Doval, J. C. L. Ecologia de reservatórios e interfaces. São Paulo: Instituto de Biociências da Universidade de São Paulo, 2015.

Ram, A. S. P.; Nair, S.; Chandramohan, D. Seasonal shift in net ecosystem production in a tropical estuary. Limnology and Oceanography, v. 48, n. 4 , p. 1601-1607, 2003. https://doi.org/10.4319/lo.2003.48. 4.1601

Royer, D. L. R. A.; Berner, J. P. Climate sensitivity constrained by $\mathrm{CO}_{2}$ concentrations over the past 420 million years. Nature, v. 446, p. 530-532, 2007. https://doi.org/ 10.1038 /nature05699

Santos, M. A.; Matvienko, B.; Rosa, L. P.; Sikar, E. Carbon dioxide and methane emissions from hydroeletric reservoirs in Brazil. Rio de Janeiro: Eletrobras, COPPE/UFRJ, 2005. 
Santos, M. A.; Rosa, L. P.; Matvienko, B.; Santos, E. O.; Rocha, C. H. E. A.; Sikar. E.; Silva, M. B.; Junior, A. M. P. B. Emissões de gases de efeito estufa por reservatórios de hidrelétricas. Oecologia Brasiliensis, v. 12, n. 1, p. 116-129, 2008.

Sbrissia, R. C. Emissão de gases de efeito estufa de reservatórios de pequenas centrais hidrelétricas: estudo de caso $\mathrm{PCH}$ Salto Natal, Campo Mourão. Curitiba: Universidade Federal do Paraná, 2008. (Dissertação de mestrado).

Sikar, E.; Matvienko, B.; Ssantos, M. A.; Rosa, L. P.; Silva, M. B.; Santos, E. O.; Rocha, C. H. E. D.; Bentes Jr., A. P. Tropical reservoirs are bigger carbon sinks than soils. Verhandlungen Internationale Vereinigung für Theoretische und Angewandte Limnologie, v. 30, Pt. 6, p. 838840, 2009. https://doi.org/10.1080/ 03680770.2009 .11902252

Silva, J. J. L. S.; Marques, M.; Damásio, J. M. Impactos do desenvolvimento do potencial hidroelétrico sobre os ecossistemas aquáticos do Rio Tocantins. Ambiente e Água, v. 5, n. 1, p. 189-203, 2010.

Souza, L. B.; Zanella, M. E. Percepção de riscos ambientais: teoria e aplicações. Fortaleza: Edições UFC, 2009.

Souza, M. B. D.; Galvani, E. Formação de lagos artificiais e influências em microclimas: revisão bibliográfica. Anais do $12^{\circ}$ Encuentro de Geógrafos de America Latina, Montevideo, 2009.

St. Louis, V. L.; Kelly, C. A.; Duchemin, E.; Rudd, J. W. M.; Rosenberg, D. M. Reservoir surfaces as sources of greenhouse gases to the atmosphere: A global estimate: Reservoirs are sources of greenhouse gases to the atmosphere, and their surface areas have increased to the point where they should be included in global inventories of anthropogenic emissions of greenhouse gases. BioScience, v. 50, n. 9, p. 766-755, $2000 . \quad$ https://doi.org/10.1641/00063568(2000)050[0766:RSASOG]2.0.CO;2

Teixeira, W.; Fairchild. A. T. R.; Toledo, M. C. M.; Taioli, F. Decifrando a Terra. São Paulo: Companhia Editora Nacional, 2009.

Verburg, P.; Hecky, R. E.; Kling, H. Ecological consequences of a century of warming in Lake Tanganyika. Science, v. 301, n. 5632, p. 505-507, 2003. https://doi.org/10.1126/ science. 1084846

Vieira, A. C. F. A polidez climática através das Conferências das Partes: ensaio político. Revista Brasileira de Gestão Ambiental e Sustentabilidade, v. 5, n. 9, p. 75-87, 2018. https://doi.org/10.21438/rbgas.050905

Wetzel, R. Gradient-dominant ecosystems: Sources and regulatory functions of dissolved organic matter in freshwater ecosystems. Hydrobiology, v. 229, n. 1, p. 181-198, 1992. https://doi.org/10.1007/BF00007000

Zheng, H.; Zhao, X.; Zhao, T.; Chen, F.; Xu, W.; Duan, X.; Wang, X.; Ouyang, Z. Spatialtemporal variations of methane emissions from the Ertan Hydroelectric Reservoir in Southwest China. Hidrological Processes, v. 25, n. 9, p. 1391-1396, 2011. https://doi.org/10.1002/hyp.7903 